\title{
Arte e publicidade na contemporaneidade: convergências
}

\author{
Bruna Berger \\ UFSM - Universidade Federal de Santa Maria
}

\section{Resumo}

Este artigo apresenta uma análise dos trabalhos artísticos dos artistas Felix Gonzalez-Torres, Jeff Koons, Barbara Kruger e Gisele Beilgueman, a fim de compreender os processos de convergência entre a arte e a publicidade na contemporaneidade. Os trabalhos artísticos que permitem a convergência com outros campos, como o da publicidade, principalmente aqueles que ocorrem em espaços não institucionais, contribuem para o debate sobre a própria natureza artística. Consequentemente, percebe-se que o público não especializado tem acesso facilitado a essas obras, o que indica uma maior democratização da arte. Compreende-se também que, embora não exista uma fusão entre a arte e a publicidade, as fronteiras entre elas se apresentam menos distintas e hierarquizadas, ou seja, mais permeáveis.

Palavras-chave: Arte contemporânea. Convergência. Publicidade. Tecnologia.

\section{Abstract}

This paper presents an analysis of the artwork of artists Felix Gonzalez-Torres, Jeff Koons, Barbara Kruger and Gisele Beilgueman with to understand the processes of convergence between art and advertising nowadays. The artworks that allow convergence with other fields, such as advertising, especially those that occur in non-institutional spaces, contribute to the debate on own artistic nature. Consequently, it is clear that the non-expert public have easier access to these works, which indicates a greater democratization of art. It is understood also that, although there is a fusion between art and advertising, the boundaries between them appear less distinct and hierarchical, or in other words, the boundaries are more permeable. Keywords: Contemporary art. Convergence. Advertising. Technology. 


\section{Introdução}

A contemporaneidade compreende um processo ativo de confluências e hibridismos culturais e comunicacionais, motivados pela exposição cada vez mais latente dos meios de comunicação de massa e das novas tecnologias. Observa-se um notável avanço da arte na utilização de estratégias para inserir e divulgar seus conteúdos nas mídias, tanto como um meio de promoção dos trabalhos artísticos como uma crítica a essas mídias. Para análise e desenvolvimento desse estudo, trazemos artistas cujas obras comportam características que levam ao esmaecimento de fronteiras entre a arte e a publicidade, permitindo visualizar aí a convergência entre ambos os domínios nos dias de hoje. A arte contemporânea é aqui entendida como um campo de saber capaz de nos proporcionar diferentes reflexões sobre o mundo, que apresenta uma posição ambígua por ser uma atividade com finalidade sem fim e que tem, no entanto, o poder de se transformar aos interesses do mercado de consumo. Enfim, acreditamos que os trabalhos artísticos que permitem a convergência com outros campos, como o da publicidade, principalmente aqueles que ocorrem em espaços não institucionais, contribuem para o debate sobre a própria natureza artística. Com isso, percebe-se uma facilidade de acesso do público não especializado a essas obras, o que indica uma maior democratização da arte.

Se desde o surgimento da publicidade existiu um diálogo dessa atividade com a arte certificado pela contribuição de artistas empenhados em criar ilustrações para cartazes e anúncios, reconhecemos que com as novas tecnologias, essa proximidade parece mais evidente, porém não menos complexa. Consideramos que essa convergência parece ter tido um grande impulso a partir da invenção das novas técnicas de reprodução. Em razão da exposição cada vez mais latente dos meios de comunicação de massa e das novas tecnologias, a arte, as imagens de massa e os produtos do mercado de consumo passaram a disputar os mesmos espaços, em alguns casos compartilhar os mesmos códigos e linguagens.

Estaria a publicidade competindo espaço com a arte ao ponto de tornar-se uma rival indesejada numa tentativa de romper as fronteiras existentes entre elas? Este fato nos conduz à apreensão de Belting (2006) com relação à imagem da publicidade e ao lugar da arte hoje. Para esse autor, "[...] não se trata de como a arte se comporta diante da cultura de massas, mas se a cultura de massas ainda concede à arte um domínio próprio" (Ibid., p. 110). O autor nos questiona se a arte ainda teria um espaço legítimo na sociedade, diante de tantos produtos culturais e de massa que com ela se relacionam, a exemplo da publicidade.

Uma das razões para a convergência da arte com o universo comercial é a utilização das técnicas e tecnologias da comunicação pelo universo artístico. Por meio da midiatização da arte, temos uma modificação da relação do público com as obras e os artistas. A utilização das técnicas e tecnologias da comunicação é uma característica preponderantemente da arte contemporânea, ela desloca o sempre presente desejo e possessão do público pela arte, uma vez que essa possessão estava ao alcance apenas de uma 
parcela pequena de pessoas poderosas, incluindo o poder público, o que passou a mudar a partir do surgimento dos meios de comunicação. "Pero ahora la reproducción pone al alcance de cualquiera la imagen de las obras, y con ello convierte el arte, así como todos los bienes de cultura en general, en objeto de consumo masivo" (JIMÉNEZ, 2002, p. 35).

Assim, que relações existem entre a arte e a publicidade que permitam elucidar a convergência entre esses dois campos de atividade humana portadores de objetivos tão diferentes? Refletir sobre os entrecruzamentos desses dois domínios seria talvez uma maneira de renovar o pensamento neste tempo tecnológico da criação contemporânea. Buscamos analisar obras artísticas que permitem visualizar a convergência entre a arte e a publicidade a partir de pelo menos dois movimentos realizados pelos artistas: a exploração da publicidade e a apropriação de linguagens e espaços publicitários. As obras aqui apresentadas são dos artistas Felix Gonzalez-Torres, Jeff Koons, Barbara Kruger e Gisele Beiguelman.

O intuito da análise repousa na apresentação de uma reflexão, na criação de uma nova imagem sobre as obras dos artistas aqui apresentadas, visando a neutralidade da questão do valor das obras de arte. Entendemos que ao analisarmos obras de arte contemporâneas estamos também realizando um movimento de análise do próprio sistema artístico e ampliando a compreensão que temos da própria arte atual. Essa ação parece ir de encontro à ideia de Jimenez (2003) de considerar e valorar nas análises estéticas a utilização de novos materiais nas obras de arte contemporâneas, a exemplo das mídias e tecnologias comunicacionais, como veremos a seguir.

\section{A arte em outdoor de Felix Gonzalez-Torres}

Felix Gonzalez-Torres nasceu em Guáimaro, Cuba, em 1957, e cresceu em Porto Rico, onde inicou a sua formação no campo da arte. O artista morreu em 1996, aos trinta e oito anos de idade, em decorrência da aids, em Miami. O trabalho de Felix GonzalezTorres, em geral, apresenta materiais cotidianos, pilhas de papel, quebra-cabeças, balas, cordas, entre outros, além de possuir uma linguagem sintética, abordando temas como amor, perda, doença, rejuvenescimento, gênero e sexualidade. Uma característica interessante sobre o qual se torna necessário comentar é que muitos dos trabalhos de Félix são homenagens ao seu companheiro Ross Laycock, que morreu também vítima da aids em 1991. Talvez por isso o conjunto das obras de Gonzalez-Torres parece repousar nos conceitos de pertencimento, de entrega, de companheirismo, sobretudo na esfera do amor, bem como de seu oposto, o sentimento de vazio, no sentido da solidão e da incompletude. Aliás, com suas obras, o artista também trata de temas relacionados ao social e ao político, a exemplo de outra obra Untitled (Figura 1), de 1991, parte de projeto de arte pública patrocinado pelo Museu de Arte Moderna (MoMA), apresentada em 24 locações de Nova Iorque, entre maio e junho de 1992. Com essa obra o artista não só 
apresenta a sua intimidade como também chama a atenção para temas de importâncias sociais e políticas muitas vezes tidas como tabu - o sexo, o homossexualismo, a aids e a morte.

A imagem estampada no outdoor é de autoria do artista, retrata em preto e branco a sua própria cama vazia, com vestígios de dois corpos ausentes. Os travesseiros amassados parecem ter sido recentemente usados por duas pessoas, bem como também os lençóis amarrotados são indicativos de um espaço compartilhado pelo artista e o seu

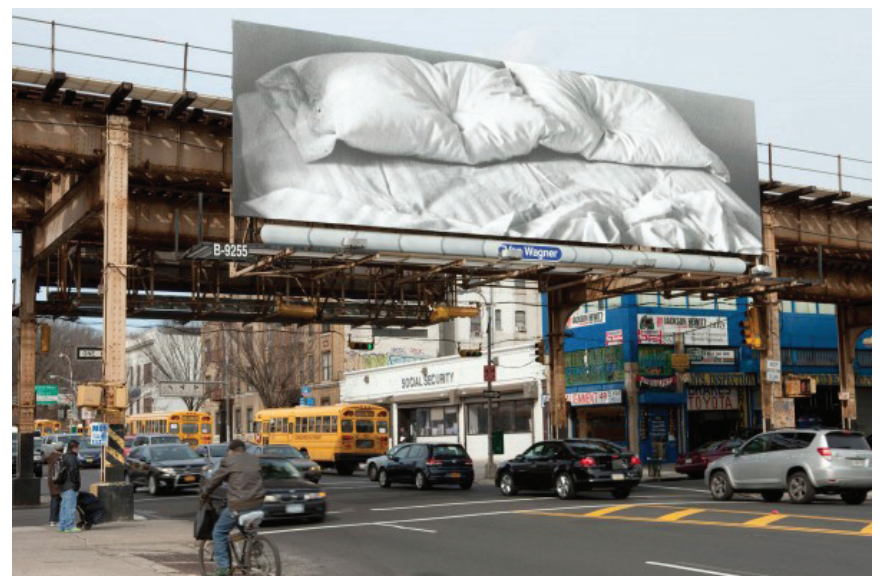

Fig. 1 - Untitled, 1991, Billboard, Installation view of Felix Gonzalez-Torres. Fonte: Site institucional do Moma.

companheiro, Ross. Olhando rapidamente, aos olhos de um transeunte qualquer, esta imagem poderia ser entendida como um anúncio de uma marca de roupa de cama, por exemplo. Porém, com essa obra, Gonzalez-Torres retrata parte da sua vida privada ao público: "In exposing the private to the public as he did with this particular billboard, Gonzales-Torres gave voice to a marginalised and stigmatised social group by calling attention to contradictory attitudes [...]" (GIBBONS, 2005, p. 92). As atitudes contraditórias que a imagem suscita parecem ser: a celebração de um momento de acoplamento e de prazer e, por outro lado, a exposição do leito de morte do amante do artista e o consequente sentimento de mortificação já que, infortunadamente, Ross morreu em decorrência de uma doença contraída em um desses momentos de celebração, de sexo.

Portanto, a afirmação do artista como um homossexual e soropositivo é nítida nesse trabalho, considerando-se, tal como afirma Vettese (2012), a história privada de Félix Gonzalez-Torres. Isto quer dizer que provavelmente sem o conhecimento das dores amorosas e físicas sofridas pelo artista não seríamos capazes de compreender a sua obra dessa maneira, estando ela aberta a outras interpretações, instigando até mesmo a pergunta: isto é arte? Outro exemplo é dado pela artista norte-americana Tammy Rae Carland. Ela conta que a primeira vez em que teve contato com a obra de Gonzalez-Torres foi quando viu o outdoor na rua: "Eu nem tinha certeza de que aquilo era mesmo arte" 
(THORNTON, 2015, p. 84). Curiosamente, um dos trabalhos produzidos por Carland posteriormente, Lesbian Beds (2002), presta homenagem a essa obra.

Gibbons (2005) acredita que a obra de Gonzalez-Torres compreende dois níveis, o pessoal e o político. Por aludir ao tema da política sexual da aids, tal trabalho também poderia ser classificado como uma arte ativista. Nas palavras de Gonzalez-Torres a arte ativista seria: "A type of art that has a preoccupation with giving diferente voices a chance to be heard and valued; a type of art that is concerned with trying to make this place a better context for the larger group" (Ibid. p. 92). Mas, até que ponto essa obra isoladamente poderia ser pensada como uma arte ativista, já que apresenta somente uma imagem sintética e conceitual, sendo preciso entender o seu contexto ou mesmo a vida do artista que a produziu para compreender o seu viés político?

Relacionando a obra de Gonzalez-Torres com as imagens da história da arte, lembra-se de Henri de Toulouse-Lautrec e a sua obra A cama (1892), que trata de uma cena íntima em que estão duas mulheres de cabelo curto, provavelmente profissionais do sexo, recém-acordadas sob uma cama, em um bordel. Outra obra que podemos associar a esse trabalho é My Bed (1998), da artista Tracey Emin, um autorretrato em forma de instalação, no qual encontramos uma cama desfeita, lençóis e travesseiros abarrotados e manchados, restos de cigarro, garrafas de bebida alcoólica, roupas íntimas sujas de sangue, preservativos usados, entre outros objetos em sua maioria desprezíveis. A imagem também pode ser associada a um dos anúncios da campanha United Colors of Benetton, criada pelo fotógrafo italiano Oliviero Toscani, no qual estão o jovem David Kirby em seu leito de morte aos 32 anos de idade, acompanhado de sua família e um padre. A semelhança dos trabalhos torna-se evidente em razão dos temas compartilhados, tais como a aids, a morte e a imagem de uma cama.

Gibbons (2005) sugere que a imagem de Felix Gonzalez-Torres incorpora o sublime, não só em razão da relativa falta de forma dessa imagem, como também por não representar de modo escrachado a dor, o sofrimento, a morte, tal qual encontramos na imagem do anúncio da Benetton. Por outro lado, essa última imagem nos direciona ao conceito de abjeto, devido à reação de repulsa e aversão que o tema da morte suscita-nos culturalmente. A obra de Gonzalez-Torres nos leva também para outra reflexão, sobre as razões da escolha do suporte outdoor para a sua obra. As características de efemeridade e de instantaneidade parecem ser uma marca de toda a produção do artista. Certamente que a sua escolha para a obra apresentada não foi ao acaso. Com essa mídia, o artista nos fala sobre a temporalidade e a brevidade da vida, uma vez que essa obra é exposta por algum tempo em vias públicas, mas tem prazo para terminar, sendo posteriormente substituída por outras imagens e levando-nos a pensar no ciclo da própria vida. 


\section{A arte em revista de Jeff Koons}

Jeff Koons nasceu em Nova Iorque, na Pensilvânia, em 1955. Koons é, até hoje, o artista vivo dono da obra mais cara vendida em um leilão, Balloon dog (Orange). Essa obra foi vendida pela Christie's, em novembro de 2013, por 58,4 milhões de dólares, um recorde para uma obra de arte, que torna o artista um dos mais caros da atualidade. Koons manobrou seu caminho de ascensão ao mercado da arte com uma "[...] estratégia digna do melhor diretor de arte de uma grande agência publicitária” (DUARTE, 2010, p. 21). O artista emprega mais de 120 pessoas em seu estúdio. Jeff Koons trabalha, sobretudo, com conceitos relacionados ao mercado artístico, tais como o gosto, o prazer, a celebridade e o comércio.

$\mathrm{O}$ artista afirma que acredita completamente na propaganda e na mídia e que a sua arte e a sua vida são baseadas nelas. Para Tomkins (2009), o ready-made é a chave para o entendimento da obra de Koons, uma vez que ele se utiliza de elementos e ícones banais e importantes da cultura de massa e os transforma em arte, além de produzir as obras em série, de modo que o valor cultural e comercial das obras não guardam relação com as suas origens materiais. Sob outro aspecto, Jeff Koons é por si só entendido como uma celebridade internacional não apenas pelo preço de suas obras. Sua fama parece ter aumentado quando, no início dos anos 1990, casou-se com a italiana Ilona Staller, na época atriz pornô e candidata à deputada, mais conhecida como Cicciolina.

Segundo Thornton (2015), Koons diz que prefere uma arte que não exija pré-requisitos, a exemplo de muitas de suas escolhas de elementos kitsch da sociedade atual utilizadas em uma série de esculturas chamada Banality. Nessa série, encontramos ursinhos de pelúcia, animais de fazenda, a Pantera Cor-de-Rosa e Michel Jackson. Para divulgar Banality, Koons se colocou em propagandas (Figura 2) “[...] o que efetivamente lançou sua persona pública, dando início a uma notoriedade subcultural que acabaria se transformando em fama disseminada." (Ibid., p. 18).
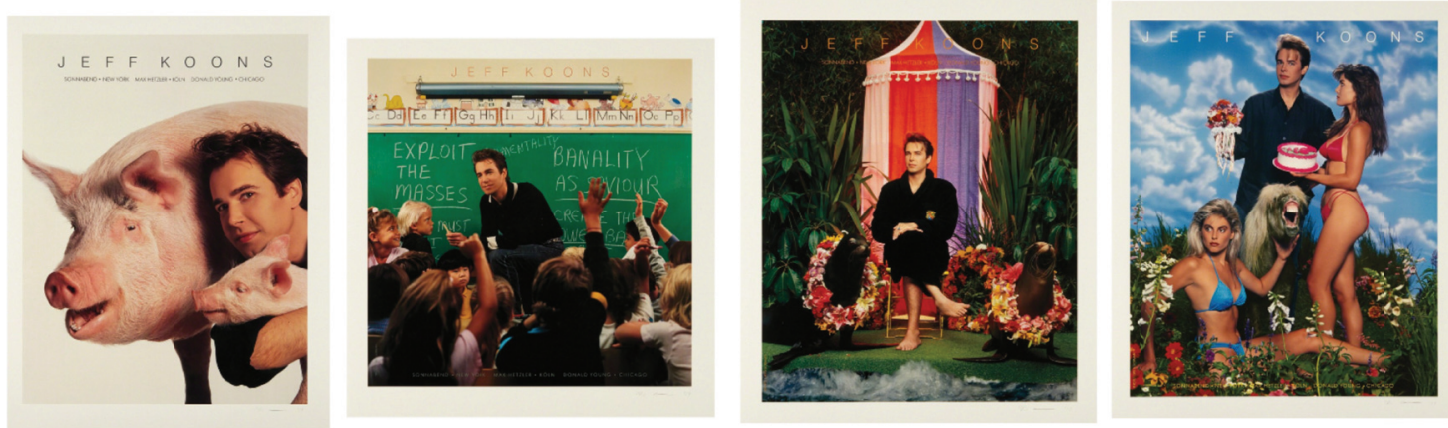

Fig. 2 - Anúncios em revistas de arte (Flashart, Art in America, Artforum, Arts), 1988, Jeff Koons, litografias coloridas, $91.4 \times 71.1 \mathrm{~cm}$. 
Esses quatro anúncios diferentes foram impressos nas mais importantes revistas de arte da época: Artforum, Art in America, ARTNews e Flash Art. Para Thornton (2015, p. 18) "As incursões de Koons na publicidade foram audaciosas, mas tinham precedente", por lembrarem uma campanha realizada pelo General Idea, trio de arte conceitual gay. "O General Idea e Koons brincam com a expectativa de que os artistas sejam exemplos de honestidade, enquanto a propaganda é o baluarte dos truques falseadores", e complementa dizendo que os artistas "Estavam questionando a posição oficial do mundo da arte, de que a obra é mais importante que o artista, e flertando com o potencial de autopromoção descarada para matar a credibilidade" (Ibid.).

Koons é o personagem principal desses anúncios, nos levando a pensar sobre os papeis dos agentes que constituem o mercado artístico. Esses anúncios parecem surgir como uma expressão de desejo de Koons em ser antes reconhecido como uma celebridade do que como um artista (GIBBONS, 2005). No primeiro anúncio, Gibbons (2005) considera que Koons antecipou a crítica popular que ele sabia que receberia, por isso utilizou-se da estratégia de satirizar a sua própria imagem e reputação fotografando-se ao lado dos porcos. No segundo anúncio, Jeff Koons parece doutrinar as crianças e explorar a sua vulnerabilidade, com a intenção de indignar os leitores de Artforum, já que a imagem ilustra um incentivo às crianças em acreditar na banalidade como salvação e como um modo de explorar as massas. Em outras palavras, Koons parece zombar das reações que o seu trabalho tem provocado na crítica, por exemplo, a ideia de que ele estaria degradando a arte ao explorar objetos banais. A obra parece imitar ou ironizar o trabalho dos quadros negros de Joseph Beuys, onde esse artista escrevia as suas ideias anti-capitalistas e anti-materialistas, a exemplo da obra Directional Forces (1974).

O terceiro e quarto anúncios se parecem mais com imagens publicitárias autênticas, já que há uma atmosfera onírica ao redor de Jeff Koons, mostrando-o, provavelmente, como uma estrela da arte. Tanto os anúncios de Koons quanto as suas obras contêm ironia, assim como percebemos essa característica na persona e no trabalho de Andy Warhol. Koons parece querer polemizar e despertar o interesse do grande público sobre a sua própria persona, desafiando o público e a própria arte. Afinal, por que os anúncios na revista não poderiam ser uma continuação do seu trabalho, uma vez que o artista trata do tema da banalidade e os anúncios são por si só considerados peças cotidianas? Resta saber qual seria a implicação da sua autopromoção para além do interesse em vender a sua imagem e o seu trabalho, mas pensando em como essa ação afeta o sistema e comportamentos artísticos. Na opinião de Gompertz (2013, p. 245), Koons removeu por completo as linhas entre a arte e a vida, retomando ao ponto em que Warhol parou, mas de modo diferente dele: "Warhol sentia-se intrigado e divertido com a ascensão da cultura das celebridades, e brincava alegremente com ela, mas, quando se tratava de sua arte, buscava apagar a si mesmo tanto quanto possível. Koons, não”.

Independente de outras implicações, uma vez que os anúncios foram publicados nas maiores revistas da arte a nível mundial, dessa forma atingindo um grande público, certamente as publicações ajudaram Koons a torná-lo amplamente conhecido, assim 
como impulsionaram a venda das obras da série Banality. Essa ação revela um grande poder de investimento do artista em sua própria divulgação no mercado de consumo, o que, coincidentemente ou não, converteu-no ao que Tomkins (2009) chama de "o novo grande astro do mundo artístico". A crítica recebeu o trabalho ora dizendo que existia uma inocência e falta de gosto ao artista, ora reconhecendo as obras como uma nova onda da pop art. "Seja como for, Banality rendeu muito dinheiro a todos e desencadeou uma torrente de retórica koonsiana, registrada em incontáveis entrevistas. Ele declarou que tudo o que havia na mostra era uma metáfora para a vergonha e a culpa do espectador" (Ibid., p. 221).

\section{A “arte-publicitária" no museu de Barbara Kruger}

Barbara Kruger nasceu em 1945, em Newark, New Jersey, nos Estados Unidos. A artista iniciou seus estudos na escola de artes visuais Syracuse University e estudou arte e design na Parson's School of Design. Nos primeiros anos de carreira, Kruger trabalhou no setor de design da revista feminina norte-americana Mademoiselle. Seu trabalho artístico aborda, sobretudo, questões relacionadas aos meios de comunicação e suas relações de controle e poder, ao mercado de consumo e ao gênero feminino. O trabalho de Barbara Kruger tem uma espécie de identidade e unicidade e, de certa forma, assemelha-se às campanhas publicitárias que apresentam elementos que se repetem. Essas características tornam possível reconhecer o seu trabalho instantaneamente, pois o estilo Kruger impõe-se. A crítica ao consumismo é clara em seu trabalho, escreve Gompertz (2013, p. 378): "Como Warhol, ela estava usando os métodos da publicidade (slogans, negrito, imagens impressionantes) para defender sua ideia. Diferentemente de Warhol, estava sendo francamente crítica em relação à indústria e sua disposição para mascatear falsas esperanças".

Kruger é bastante reconhecida por utilizar de suportes não convencionais à arte, como outdoors, ônibus, sacolas e camisetas. Entretanto, para esse trabalho, selecionamos uma obra da artista com outra abordagem. Ao contrário das obras apresentadas anteriormente, as quais se deslocam para um suporte convencionalmente não utilizado pela arte e sim pela publicidade, como é o caso do outdoor e da revista, a obra exibida a seguir utiliza uma linguagem caracteristicamente publicitária, porém é exposta em um espaço insititucional da arte, o museu. Trata-se da obra Untitled (Hello/Goodbye) (Figura 3), instalação com impressão digital em vinil aplicado e exposta no Hammer Museum, em Los Angeles, durante a exposição Take It or Leave It: Institution, Image, Ideology, que ocorreu de 27 de janeiro a 18 de maio de $2014^{1}$.

$\infty<\infty<\infty<\infty<\infty<\infty<\infty<\infty<\infty<\infty<\infty<$

1 O tema da mostra é justamente a apropriação de imagens já existentes, formas e estilos das mídias de massa e a crítica institucional, como a análise e o enfrentamento das instituições sociais, culturais e políticas. 
Essa obra apresenta vários textos de impacto, com emprego de palavras em maior destaque, as cores habituais, preto, branco e vermelho, e também o uso de imagens da mídia, como na segunda imagem, onde vemos um fundo semelhante a uma página de jornal. Com frases como "And above all... beware assuming the sterile atitude of spectator", "Demagogue is to make himself as stupid as his audience - so that they believe they're as clever as he is!" e "You. You are here to get cultured, to get smarter, richer, yonger, angrier, funnier, skinner, hipper, hotter, wiser, weirder, cuter and kinder". Kruger parece não somente realizar uma crítica aos discursos da comunicação com seus imperativos, mas também realizar uma crítica ao próprio espectador do museu e às instituições da arte. Neste caso, a artista utiliza um discurso tipicamente publicitário, porém, contraditoriamente ou não, a mensagem de sua obra parece acentuar-se como uma crítica às instituições da arte, pois paradoxalmente é instalada em uma dessas instituições.

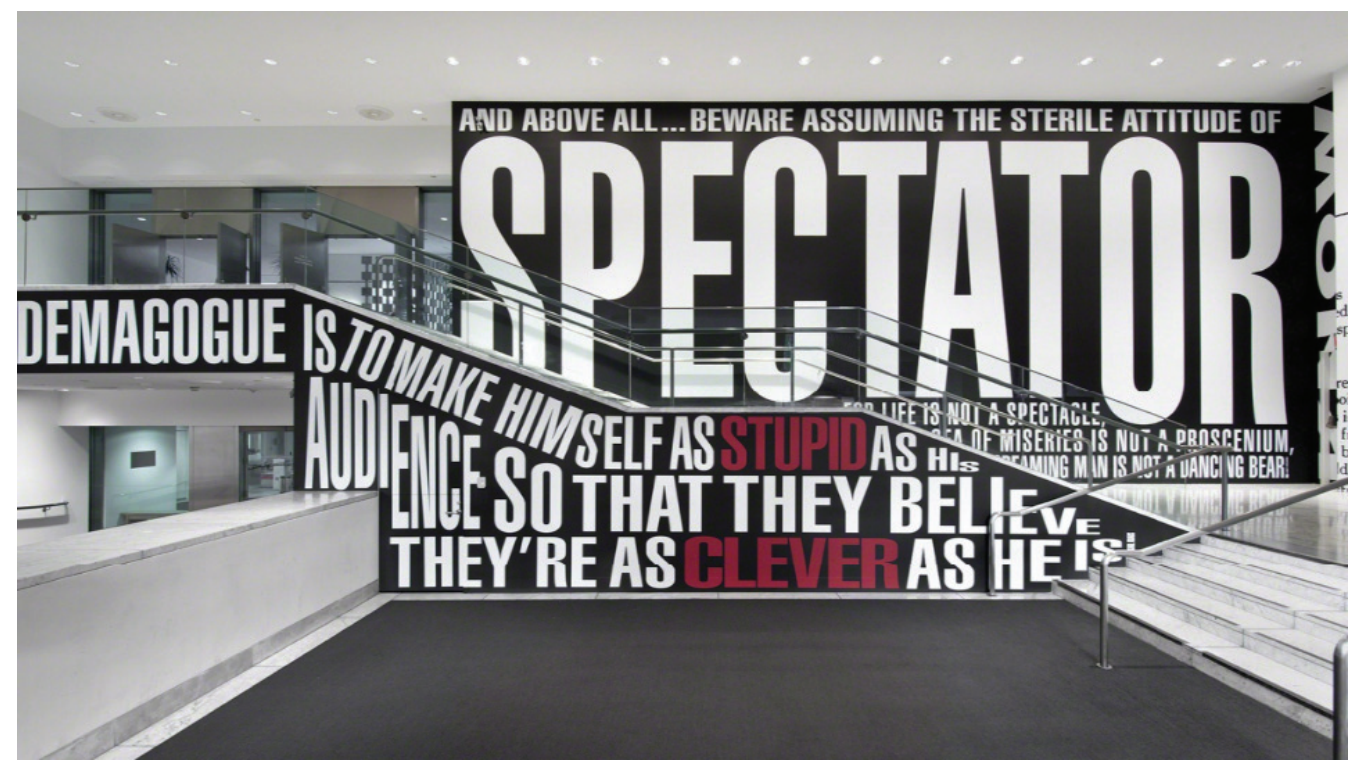

Fig. 3 - Untitled (Hello/Goodbye), 2014, digital print on vinyl, Hammer Museum. Photos: Brian Forrest. Fonte: Site Artsy.

A ação da artista em utilizar o espaço de um museu para criticar as mídias de massa parece ser capaz de afrontar o público com ainda mais força do que as imagens misturadas a outras, a exemplo das imagens banais do cotidiano, como as das ruas. Afinal, será que expondo em espaços como a rua, de modo a misturar suas obras a outras

Outros 35 artistas que se destacaram do final dos anos 1970 e início dos anos 1990 compuseram a exposição, incluindo Gonzalez-Torres. Para mais informações acessar: <http://hammer.ucla.edu/exhibitions/2014/ take-it-or-leave-it-institution-image-ideology/>. 
imagens sobre os quais recrimina, sua crítica não se enfraqueceria bem como suas obras não se transformariam também em mercadorias? A obra Untitled (Hello/Goodbye) parece possuir uma mensagem explícita sobre o comportamento do espectador da arte, utilizando-se do espaço do museu para provocar, considerando que a artista diz: "Você está aqui para obter cultura, para se tornar esperto, etc.” Será que essa obra realmente provoca e faz com que o público pense sobre o seu comportamento como espectador? Essa questão merece ser colocada, pois se ainda não há resposta, ela incita a observação e o pensamento crítico sobre a obra e, consequentemente, sobre o observador da mesma.

Ao falar sobre os paradoxos da arte política, Rancière (2010, p. 52) afirma que muitos artistas manifestam sua vontade de repolitizar a arte com estratégias e práticas diversas, sendo que todos eles possuem um ponto em comum. Geralmente os artistas consideram seguro certo modelo de eficácia: “[...] a arte é considerada política porque mostra os estigmas da dominação, porque ridiculariza os ícones reinantes ou porque sai de seus lugares próprios para transformar-se em prática social etc.". (Ibid.). Como vimos, Barbara Kruger parece empregar o discurso das mídias para criticá-las, mas também afronta o mundo da arte com semelhante discurso. Pensando com Rancière (Ibid., p. 54), será que a artista consegue resolver esse “[...] continuum sensível entre a produção de imagens, gestos ou palavras e a percepção de uma situação que empenhe pensamentos, sentimentos e ações dos espectadores"? Por estratégia ou por necessidade, a artista busca, no mínimo, criar situações instigantes que possam interpelar o espectador.

Kruger parece ser uma dessas artistas que adota estratégias que transformam referenciais e mostra o que não poderia ser visto facilmente de outro modo, correlacionando o que antes não era correlacionado, “[...] com o objetivo de produzir rupturas no tecido sensível das percepções e na dinâmica de afetos” (RANCIẼRE, 2010, p. 64). A artista cria, então, ficções, que são por sua vez um trabalho que realiza dissensos, conforme explica Rancière (Ibid.), essa ação “[...] muda os modos de apresentação sensível e as formas de anunciação, mudando quadros, escalas ou ritmos, construindo relações novas entre a aparência e a realidade, o singular e o comum, o visível e sua significação".

\section{A arte na internet de Gisele Beiguelman}

Voltamos à arte que ocupa um espaço não convencional, desta vez um espaço que se caracteriza por ser democrático, já que nele circula todo e qualquer tipo de conteúdo: a internet. Considerando a produção de arte contemporânea brasileira, Gisele Beiguelman desponta nesse cenário, sobretudo com relação à arte digital, intervenções em espaços públicos, projetos em rede e em dispositivos de comunicação móveis. A artista, professora e também curadora, nasceu em São Paulo, no Brasil, em 1962. Sua formação acadêmica é em história, porém suas pesquisas centram-se na criação e desenvolvimento de criações digitais. A artista trabalha com questões relacionadas à arte e à tecnologia, 
chamando a atenção para “[...] o nomadismo que as mídias digitais proporcionam e para a circunstância atual, em que matriz e cópia convivem simultaneamente em um único domínio" (MELLO, 2010, p. 106).

Interessa-nos aqui seu trabalho Ceci n'est pas une Nike (2002) (Figura 4), no qual Beiguelman parodia nitidamente o quadro de Magritte, onde se pode ler em francês "Ceci n’est pas une pipe", "isso não é um cachimbo", nesse caso, "isso não é um Nike". A imagem de um tênis com o célebre símbolo da marca propõe um conflito entre imagem e representação, onde o espaço da internet parece confundir ainda mais tais conceitos.

Essa obra pode ser vista no site www.desvirtual.com/nike, onde também era possível interagir com a imagem original por meio do dispositivo nomeado e-nike generator. Ao clicar no botão "Destrua um Nike", qualquer usuário podia desfigurar a imagem do tênis e o texto do modo como quisesse, respeitados os limites permitidos pela programação do site ${ }^{2}$. As imagens geradas podiam ser salvas, destruídas, publicadas ou expostas em uma galeria nesse mesmo site. A obra discute diferentes conceitos implicados ao campo da arte, assim como também aos do campo da comunicação. O site traz a referên-

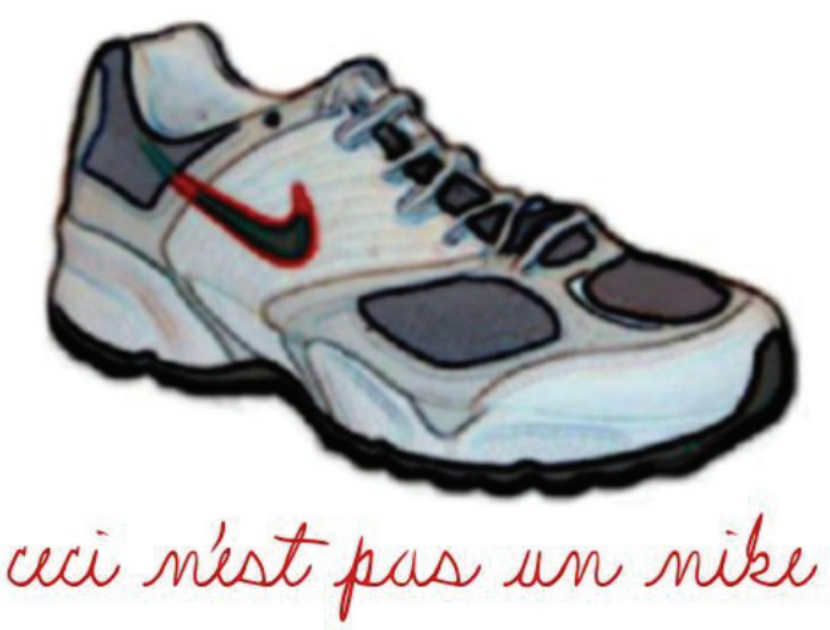

Fig. 4 - Ceci n'est pas une Nike, 2002. Fonte: Site Desvirtual.

cia ao slogan Just do it (traduzindo para o português, "apenas faça"), criado pela agência Wieden+Kennedy em 1988, nos remetendo diretamente ao universo da publicidade. No contexto da Nike, o slogan quer dizer: "mexa-se", "excercite-se", "você consegue". A expressão possui força e já está incorporada ao imaginário das pessoas, tal como o signo que resume a marca da Nike. Esses dois elementos são não apenas mundialmente reconhecidos, mas também admirados.

$\infty<\infty<\infty<\infty<\infty<\infty<\infty<\infty<\infty<\infty<\infty<$

2 Ao que parece, o sistema de interação não está mais ativo - não conseguimos desfigurar a imagem por meio do site em nenhuma das tentativas. 
Portanto, Beiguelman parece questionar o modo como incorporamos facilmente símbolos e expressões do cotidiano, tal como a marca Nike. Rancière (2012, p. 51) afirma que "Alguns artistas transformam em estátuas monumentais os ícones midiáticos e publicitários para nos fazerem tomar consciência do poder desses ícones sobre nossa percepção [...]”. É essa conotação que Beiguelman parece dar a sua obra. A artista nos leva a pensar o fato de aceitarmos tais imagens e o modo como nos comportamos, por exemplo, quando vamos à loja ou a um site de compras online e compramos um Nike, não mais um tênis da marca Nike. Beiguelman, provavelmente, propõe com essa obra que se distorça ou destrua a imagem da Nike e, implicitamente, todos os valores e símbolos implicados a essa marca. Tudo leva a crer que se trata de uma crítica ao viés do marketing e da publicidade atrelados à Nike. Ao mesmo tempo, a artista aproveita-se de tal status como força poética de sua obra. Mais ainda, conduz o público em uma direção contrária ao discurso proferido pela marca, lembrando também das falsificações do mercado de consumo.

A imagem original de Beiguelman, ao sofrer interfências realizadas por outras pessoas, provoca o debate acerca dos conceitos de original e cópia e, igualmente, sobre a autoria da obra quando há compartilhamento e interação na mesma. É certo que com a internet esses conceitos são resignificados. A própria imagem matriz de Beiguelman já parece ser uma cópia de uma imagem da Nike, contudo apresenta ruídos, como o seu símbolo invertido, lembrando, outra vez, os produtos falsificados. Ao propor que o público interaja com a obra por meio do site, percebe-se uma aparente confusão sobre as linguagens utilizadas - a programação envolve números e vários códigos próprios, que por sua vez geram imagens e novos textos e códigos. Assim, Beiguelman parece propor uma reflexão sobre a própria ação do programa que possibilita o acesso à obra e sobre o modo como agimos perante ela. Conforme analisa Mello (2010, p. 106), nesse e em outros de seus trabalhos, a artista "[...] reflete a necessidade de repensarmos novos paradigmas para a criação, assim como uma cultura híbrida, nômade, ligada à reciclagem das mídias e à sampleagem”. Afinal, ao utilizar de um símbolo como a marca da Nike e, ao mesmo tempo, ao remeter à obra de Magritte, Beiguelman realiza uma ação de samplear, recuperando imagens pré-existentes não só da arte, como também da publicidade.

Ao sugerir que o público interfira ou destrua um símbolo de status, tal qual é considerado um tênis da marca Nike na cultura de consumo, as pessoas se deparam com a marca de um modo não esperado, apreendendo uma nova ideia sobre ela, ou seja, há a possibilidade de considerá-la segundo outro ponto de vista. A artista induz as pessoas a um novo modo de ver a marca Nike e aos sentidos imbuídos nos elementos apresentados: o símbolo, a palavra e a imagem. Na verdade, nos é apresentada uma imagem resignificada da Nike e nos é feito o convite de realizar essa ação mais uma vez. Porém, não deliberadamente ao modo como quisermos, já que as ações estão limitadas pelo programa e por quem o idealizou. A plataforma e a artista oferecem o programa da distorção, mas direcionam e, de certa forma, manipulam ou restringem o modo como o público deve interagir com a obra. 
Ceci niest pas une Nike é uma obra de arte que possui um caráter híbrido devido ao trabalho conjunto de diferentes áreas do saber que colaboram para o seu desenvolvimento e devido a essa característica de convergência das mídias que a cultura digital apresenta. Passados quase quinze anos da sua criação, percebe-se o quanto o site, hoje, parece anacrônico, de difícil navegação e pouco intuitivo - algumas páginas estão em branco, mostrando que talvez a obra necessitasse de atualização. Enfim, a obra de Gisele Beiguelman suscita inúmeras questões que vão além daquelas referentes ao conteúdo formal da obra em si e da mídia utilizada, mas que comportam também questões conceituais e filosóficas. Consequentemente, analisar trabalhos dessa ordem se torna uma tarefa complexa, principalmente por tratar-se de conteúdos ainda recentes no campo da arte, nos permitindo uma distância necessária a uma análise precisa. Contudo, permear questões inerentes a esse contexto da arte atual nos leva a provocar o debate, a interrogar e a refletir, certamente sem a pretensão de encontrar respostas. Esta reflexão tem o mérito de colocar no centro da discussão o trabalho de artistas que cruzam experiências, hibridam técnicas e se servem das novas tecnologias instigando a confrontação e o pensamento no entorno de tais empreitadas, onde, por vezes, a arte e a não arte se confundem.

\section{Considerações Finais}

Por meio da análise das obras apresentadas anteriormente, pode-se perceber que, quando os artistas utilizam de espaços que não aqueles legítimos e oficiais da arte ocorrem transformações de diferentes aspectos. A maior parte dos trabalhos aqui apresentados comporta-se como um meio expansivo das produções dos artistas, por atingir um público maior e diferente daquele dos museus e galerias. O confronto das obras artísticas com as imagens de massa e, consequentemente, a sua repercussão em um território não usual, também são pontos em comum aos trabalhos analisados. Sem distinção, os artistas acabam por expandir as fronteiras da arte, estreitando relações com a comunicação e a publicidade. A utilização de novas tecnologias é explícita, seja por meio da fotografia, da internet, da apropriação de imagens da mídia e da impressão das imagens em offset em larga escala, de modo a enriquecer o panorama da produção artística na contemporaneidade.

As obras que se apresentam em outdoors, revistas e internet compartilham um espaço público que é comercializado e que veicula diferentes anúncios, os quais por sua vez vendem outros produtos, serviços e ideologias. Jimenez (2003) escreve que a arte contemporânea é uma arte que se dilui na vida banal e cotidiana, de modo a criar reações instantâneas e de experiência com o público. Com tais ações, a arte contemporânea cria um argumento pertinente e condena algumas notabilidades artísticas de caráter mais elitista. As obras de arte expostas nesses espaços, incluindo a internet, encontram um público diferente daquele que vivencia os circuitos convencionais das artes. 
Em geral, os artistas aqui apresentados parecem dizer que a arte também merece um espaço em meio ao mundo banal das imagens e, ao mesmo tempo, explicitam que a arte também faz parte do mercado de consumo, visto que os espaços para que as suas obras fossem exibidas foram pagos.

Assim, podemos admitir que a arte está mais democrática? Ao aproximar a arte das massas, os artistas diluem um pouco mais as fronteiras ou destacam as suas mensagens em meio a tantas outras das mídias? Ao discutir e se utilizar de recursos próprios dos meios de comunicação, os artistas parecem interrogar a própria natureza da arte, que passa a se confundir com a mídia e as suas tecnologias. Ainda, ao desconstruir as mensagens dos meios de comunicação ou mesmo utilizar-se de suas mídias ou sua linguagem, os artistas parecem construir uma nova linguagem no campo artístico e ampliar o lugar social da arte. Essas reflexões sobre os processos da informação repercutidos por meio das tecnologias comunicacionais são também um modo de indagar sobre o próprio sistema artístico.

O espectador já está habituado a encontrar uma ampla variedade de signos nos espaços não institucionais da arte, logo se torna disposto também a assimilar trabalhos artísticos. "En respuesta a ofertas tan variadas, el espectador ha de tomar postura y decidir constantemente con qué actitud desea participar en la obra" (VETTESE, 2012, p. 33). Para Mello (2010, p. 98) “As poéticas investigativas com as novas mídias atuam na lógica do fazer-pensar arte e tecnologia ao modo de laboratórios vivos e experimentais, nas confluências existentes entre a produção de conhecimento e a produção artística". Não há mídias privilegiadas para as artes, mas sim mecanismos de hibridação entre os meios tenológicos, os quais geram "estranhamento por meio de zonas de tensão entre sistemas midiáticos" (Ibid.).

Ao utilizar-se das tecnologias, os artistas trazem o questionamento e o debate sobre a própria natureza da arte, provocando também questões relacionadas ao mercado de consumo e ao sistema publicitário, relevando, muitas vezes, um conteúdo de viés político em seus trabalhos. Este é o exemplo da obra de Kruger, que apresenta uma contradição, ao mesmo tempo em que a artista critica as imagens e mensagens veiculadas massivamente, utiliza de uma linguagem semelhante e empregada por elas. A relação que o público tem com essas mensagens é novamente modificada. Por outro lado, a artista parece também colocar em questão a essência da obra de arte contemporânea e suas relações com a lógica e as estratégias comerciais.

Portanto, nas obras aqui analisadas, os artistas questionam e criticam não só o mercado de consumo, mas também o mercado da arte. No caso da crítica ao mercado de consumo, de modo controverso, passam a adotar as suas técnicas e estratégias. Alguns artistas parecem reconhecer e se valer da arte como parte da cadeia generalizada do consumo, como Jeff Koons, por usufruir de meios de comunicação bem visitados em suas obras, para uma exposição de sua própria persona artística, encontrando, assim, o máximo de visibilidade e popularidade. A obra de Felix Gonzalez-Torres, apesar de retratar um drama pessoal, antes parece refletir o desejo de conquistar e legitimar o seu 
trabalho em espaços não tradicionais à arte do que ganhar alguma visibilidade. Assim, a arte recorre ora ao escandaloso, ora ao sutil, utilizando por contaminação práticas e procedimentos tomados das estratégias dos meios de comunicação.

Acrescentamos que a arte, a sua maneira, está implicada a uma economia do sistema tanto quanto a publicidade, mas o que se torna mais evidente é que a arte é geralmente muito mais exclusiva e elitista e menos democrática e acessível do que a publicidade. Assim, os processos de convergência contribuem para a proliferação e a divulgação dos objetos artísticos e, consequentemente, indicam uma maior democratização da arte. Isto é notável pelo fato de os trabalhos artísticos aparecerem cada vez mais em espaços públicos e não institucionais, aproximando-se de um amplo público, sobretudo não especializado em arte. A relação do público com a arte, portanto, se altera, principalmente quando ela é exposta em locais não legítimos, como nos outdoors, nas revistas e na internet.

Ao usar de espaços não legítimos da arte como os meios de comunicação, a arte contemporânea se aproxima de uma linguagem mais acessível, apesar de alguns autores ainda considerarem que o público necessita de certos códigos para compreendê-la, quando, de outro lado, a publicidade parece não apresentar pré-requisitos para o seu entendimento. De todo modo, a arte necessita de um público abrangente para sobreviver, e esta é uma das razões do surgimento de novas possibilidades para sua exposição. Consequentemente, é proporcionado ao público um maior diálogo e uma valorização de sua sensibilidade e, aos artistas, amplia-se o espaço de atuação e exposição de suas obras.

Embora não exista uma fusão entre a arte e a publicidade, as fronteiras entre elas se apresentam menos distintas e hierarquizadas, mais permeáveis. Esse fenômeno modifica a experiência estética que temos com o mundo, isto porque, em convergência com outros domínios, a arte contribui para tornar as pessoas mais progressistas e sensíveis. Assim, a arte voltada para as elites parece dar lugar a uma arte mais acessível e democrática. O público, por sua vez, parece que tem muito a ganhar com a ampliação da exposição da arte nas mídias, pois o seu contato com esse modo de expressão torna-se um acontecimento. Esse tipo de arte que converge com outros domínios, como o da publicidade, aparentemente diferencia-se da arte culta e de elite e se faz importante para diversificar as produções contemporâneas e por permitir, de certa forma, uma politização da cultura.

\section{Referências bibliográficas}

BELTING, Hans. O fim da história da arte: uma revisão dez anos depois. Tradução Rodnei Nascimento. São Paulo, Cosac Naify, 2006.

DUARTE, Paulo Sergio. Apresentação à edição brasileira. In: SIEGEL, Katy; MATTICK, Paul. Arte \& Dinheiro. Tradução Ivan Kuck. Rio de Janeiro: Editora Zahar, 2010. 
GIBBONS, Joan. Art \& Advertising. New York: I.B. Tauris, 2005.

GOMPERTZ, Will. Isso é arte? 150 anos de arte moderna do impressionismo até hoje. Tradução Maria Luiza X. de A. Borges. 1. ed. Rio de Janeiro: Zahar, 2013.

JIMÉNEZ, José. Teoría del arte. Madrid: Editorial Tecnos, 2002.

JIMENEZ, Marc. Pós-modernidade, filosofia analítica e tradição europeia. In: ZIELINSKY, Mônica. Fronteiras: arte, críticas e outros ensaios. Porto Alegre: Editora da UFRGS, 2003 (p. 55 - 88).

MELLO, Christine. Arte e novas mídias: práticas e contextos no Brasil a partir dos 1990. In: Téknne. MATTAR, Denise; MELLO, Christine. Fundação Armando Alvares Penteado, 2010.

RANCIÈRE, Jacques. O espectador emancipado. São Paulo: Editora WMF Martins Fontes, 2012.

THORNTON, Sarah. O que é um artista? Nos bastidores da arte contemporânea com Ai Weiwei, Marina Abramovic, Jeff Koons, Maurizio Cattelan e outros. Rio de Janeiro: Zahar, 2015.

TOMKINS, Calvin. As vidas dos artistas. Tradução Denise Bottmann. São Paulo: BEI Comunicação, 2009.

VETTESE, Angela. El arte Contemporáneo: entre el negocio y el lenguaje. Madrid: Ediciones, Rialpp, S. A., 2013.

\title{
Webgrafia
}

\author{
artmuseum.princeton.edu \\ artsy.net \\ barbarakruger.com \\ desvirtual.com/nike \\ hammer.ucla.edu \\ jeffkoons.com \\ moma.org
}

